\title{
AUTOMATION OF ENTERPRISE AUDIT MANAGEMENT SYSTEM
}

\author{
Prashant P.Suryawanshi ${ }^{1}$, Jayalaxmi G.N ${ }^{2}$ \\ Department of Computer Science, \\ B.V.B. College of Engg \& Technology,Hubli, India. \\ Email: ${ }^{1}$ sssprashant11@gmail.com, ${ }^{2}$ jaya_gnebvb.edu
}

\begin{abstract}
In earlier days auditing was by an independent person or body of persons with the help of vouchers, documents, information and explanations received from the authorities, for the purpose of ascertaining whether the works done entered in the books are genuine and have been entered with proper authority. It was done manually. Its job is also to find out whether they are accurate and that the works are done in accordance with law and rules and regulations of the organization in particular the standards and standard auditing practices. This drawback can be overcome using automating tool that is Automation of Enterprise Audit Tool.The Audit Tool keeps the track of the works done and intimates to higher authority if the works are not done.This application helps to manage various works in the organization And it helps to intimate the higher authority in case of the work is not done. The software "Audit Tool" helps to store the details of any enterprise and the process carried out at that enterprise.
\end{abstract}

\section{KEYWORDS}

Audit- Auditing is defined as a systematic and independent examination of data, statements, records, operations and performances (financial or otherwise) of an enterprise for a stated purpose.

\section{INTRODUCTION}

Internal Audit is a tool of control to measure and evaluate the effectiveness of the working of an organization primarily with accounting, financial and operational matters. The job of internal audit is to ensure that the work of the company is going on smoothly, efficiently and economically and that all the laws, rules and regulations governing the operations of the organization are adhered to, besides ensuring that an effective internal control system exists to prevent errors, frauds and misappropriations . Currently all organizations want to keep a track of all the works done at the organization. Audit tool helps in the management of the works at the organization. It helps to keep the track of the works done and intimates to higher authority if the works are not done.In earlier days auditing was by an independent person or body of persons with the help of vouchers, documents, information and explanations received from the authorities, for the purpose of ascertaining whether the works done entered in the books are genuine and have been entered with proper authority. It was done manually. Its job is also to find out whether they

Sundarapandian et al. (Eds) : CCSEIT, DMDB, ICBB, MoWiN, AIAP - 2014

pp. 31-38, 2014. @ CS \& IT-CSCP 2014

DOI : 10.5121/csit.2014.4805 
are accurate and that the works are done in accordance with law and rules and regulations of the organization in particular the standards and standard auditing practices.This drawback can be overcome using the Automation of Enterprise Audit Management System.

The Advantages of Automating Enterprise Audit management are, Audit Helps To Detect And Prevent Errors And Frauds,Audit Helps To Maintain Account Regularly,Audit Helps To Get Compensation,Audit Helps To Present a Proof,Audit Provides Information About Profit Or Loss,Audit Helps To Prepare Future Plan.

The applications Automating Enterprise Audit Management System are Audit Tool is used in any Enterprise organizations, Audit Tool is used in Hospital management, Audit Tool is used in the Education Department.

The Proposed System of Automating Enterprise Audit tool works in the computerized environment and has become more relevant so as to make the audit personnel very effective in detecting irregularities. It is the examination of all managerial performance. In our audit tool system all the works done or not done can be checked online. In our system any new enterprise can registers to the system. Once the new enterprise registers to the system, the super admin has the authority to activate or delete the newly registered enterprise. The super admin also has the authority to deactivate or reactivate already registered enterprises. Once the super admin activates the newly registered enterprises a mail will be sent to that respective enterprise informing about the url, username and randomly generated password of the enterprise. The password is encrypted using MD5 encryption and stored in the database. Here the enterprise admin can add, view, edit and deletes department, stakeholder, process, checklist online. In our system as soon as the enterprise admin adds a stakeholder a mail will be sent to his/her email id informing that he has been added to so and so department with a particular role assigned to him. In our system when the enterprise admin adds a process he assigns a stakeholder to that process and as soon as the stakeholder is assigned to a process he will get a mail informing to which process he is being added. The supervisor fills the checklist online and the functional admin gets the mail of the works that have not been done along with the reason. The functional admin gets the mail continuously till the works are done. These mails are sent using crontab jobs.

The Author organizes the article in the following manner, Related Work, Proposed System, Proposed System, Conclusion and finally References.

\section{RELATED WORKS}

\subsection{Energy Audit Tool}

Author's from Green Leader's [1] and [2] about Energy Audit Tool explained as follow's. Energy audit is a crucial activity in every energy management strategy. Specific technical skills are required to efficiently perform audits of buildings. A software tool has been designed and implemented that should support every step of an exhaustive audit focused on energy usage in buildings. The software program is implemented on PDA in order to provide a portable tool that is useful for in field surveying activities. The program is structured in several procedures each focused on surveying a specific energy usage in the building. Particular attention has been given in the paper to the illustration of two particular procedures of the program that are more directly linked with electricity usage: lighting and office equipment. 


\subsection{Capacity Audit Tool}

Author's from Asian Development Bank (ADB). 2007a[3] and Department for International Development (DFID). 2005. [4] explained as follows about the Capacity Audit Tool. This tool was developed out of an identified need from within the organization to create a common understanding of capacity building. On the one hand, the tool could be used by GeSCI staff in assessing its internal capacity to not only carry out its day-to-day operations but also in its capacity to offer strategic advice to its partner countries. On the other hand, the tool could be used by GeSCI while assessing the capacity of the Ministries of Education to carry out their dayto-day activities in relation to ICT4E or in executing a defined project in the same context.

\subsection{District Audit Tool}

Author's Abedi, J., Lord, C, Hofstetter, C., \& Baker, E. (2000) [5] and Acquarelli, K., \& Mumme, J. A. (1996) [6] explains the following about District Audit Tool. The No Child Left Behind (NCLB) Act of 2001 requires States to make adequate yearly progress (AYP) determinations for all districts/schools to develop school support systems for schools that do not make AYP and to provide direct support to districts in need of improvement under AYP. Given that the proportion of schools and districts likely to be identified under AYP criteria are likely to continue to increase rapidly, most States lack the capacity in fiscal and human resources to deliver uniform levels of quality support to all identified districts and to other districts in their delivery of support to schools. The support needed should be of a nature and quality that can reasonably be expected to lead to significant improvement. In addition, the same assistance may not be needed and may, in fact, interfere with the districts' progress if the assistance is inappropriate or distracting from the problems that resulted in the failure to meet AYP in the first place. Although technical assistance is provided in some form for every district missing AYP targets for two consecutive years, the intensity and the focus of assistance will vary depending on level of need and each district's specific barriers to success.

\subsection{Road Safety Audit Tool}

The Author's Blind Citizens Australia (2009) [7] and

Garrard, J (2013) [8] explained the following about the Road Safety Audit Tool. The document provides an accessible but comprehensive tool for assessing the walkability and safety of road environments for pedestrians with vision impairment. It is designed to be used by anyone who has an interest in road safety for people with vision impairment, from traffic engineers to volunteer advocates. It is also designed to facilitate reporting of issues in a way that gives road management authorities a comprehensive picture of the road environment as it relates to pedestrians who are blind or have low vision.information.

\subsection{Manufacturing Audit to Improve Quality}

\section{Performance - A Conceptual Framework}

The Author's Arter D.R. (1994) [9] and Askey, J M and Dale, B G (1994) [10] explains the following about Manufacturing Audit. Manufacturing process audit is one of the many quality tools to assess the effectiveness of manufacturing process and quality performance. They are commonly used in the effort to diagnose, maintain and improve quality management system. It is 
made compulsory for the organization to maintain their quality management system based on ISO9001 standard to conduct an internal audit. However, similarly to any other physical or conceptual system, they may fail to achieve the objectives set forth, to assess effectiveness and at the same time fail to recognized area for improvement. Based on an extensive literature review, the issues relevant to manufacturing audit and quality performance are examine, and discussed the several issues to identify the conceptual framework of manufacturing audit.

\section{PROPOSED SYSTEM}

This project is about developing a software named "Enterprise Audit Management".This software can be used by any organization to keep the rack of all works at their organization. To use this software, the organizations should first register their organization with this software. Once the organization is activated they can start using the software. This software is an independent entity and has its own database and hence not dependant on any other softwares. This software helps to maintain the details of the stakeholders and keeps the track of works of that organization.

\section{Architechture Diagram}

This software is an independent entity and has its own database and hence not dependant on any other softwares. This software helps to maintain the details of the stakeholders and keeps the track of works of that organization

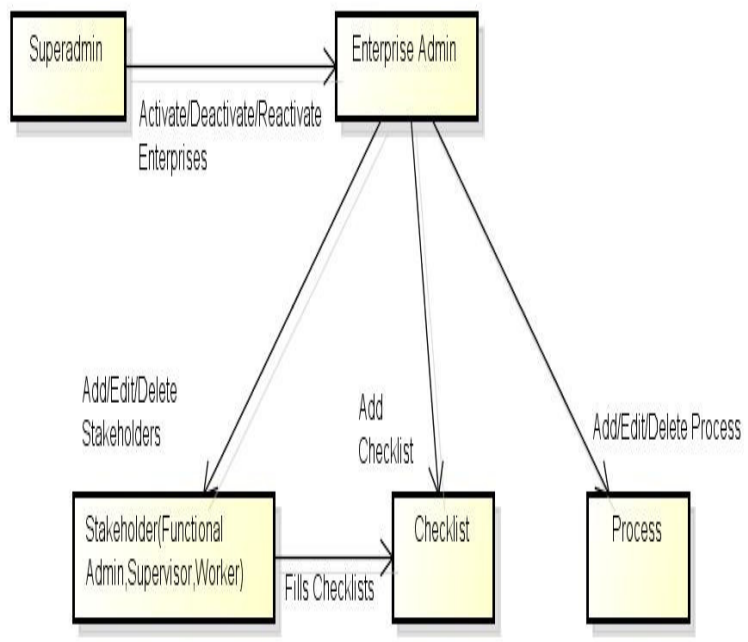

Fig.1 Architecture diagram

\section{Super Admin:}

- Manage activation, deactivation and reactivation of users (organizations).

\section{Enterprise Admin:}

- Registers his organization for the use of the audit tool.

- Creates different departments for his organization. 
- View and edit the departments.

- Create stakeholder profile with role assigned to each stakeholder.

- View and edit stakeholder profile.

- Create process details and assign stakeholders to each process.

- View and edit process details.

- Create checklist for each process.

- View and edit checklist.

\section{Functional Admin:}

- Fills the checklist regarding a particular process within a given time period if not done by the supervisor.

\section{Supervisor:}

- Fills the checklist regarding a particular process within a given time period and send mail to the respective functional admin regarding the status of that process.

\section{Algorithm 1:MD5 Encryption}

MD5 is an algorithm that is used to verify data integrity through the creation of a 128-bit message digest from data input (which may be a message of any length) that is claimed to be as unique to that specific data as a fingerprint is to the specific individual. MD5, which was developed by Professor Ronald L. Rivest of MIT, is intended for use with digital signature applications, which require that large files must be compressed by a secure method before being encrypted with a secret key, under a public key cryptosystem. MD5 is currently a standard, Internet Engineering Task Force (IETF) Request for Comments (RFC) 1321. According to the standard, it is "computationally infeasible" that any two messages that have been input to the MD5 algorithm could have as the output the same message digest, or that a false message could be created through apprehension of the message digest. MD5 is the third message digest algorithm created by Rivest.

\section{MD5 Algorithm}

\section{Step 1: Append padded bits}

The message is padded so that the length is congruent to 448 modulo 512. A single "1" bit is appended to a message and then " 0 " bits are appended so that the length in bits equals 448 modulo 512.

\section{Step 2: Append length}

A 64 bit representation of $b$ is appended to the result of the previous step. The resulting message has a length that is an exact multiple of 512 bytes. 


\section{Step 3: Initialize MD buffer}

The four word buffer (A,B,C,D) is used to compute the message digest. Here each of A, B, C, D, is a 32 bit register. The registers are initialized to the following values in hexadecimal:

word A: 01234567

word B: $89 \mathrm{ab}$ c def

word C: fe dc ba 98

word D: 76543210

\section{Step 4: Process message in 64 word blocks}

Four auxiliary function that take as input 3 32-bit words and produce as output 132 bit word.

$\mathrm{F}(\mathrm{X}, \mathrm{Y}, \mathrm{Z})=\mathrm{XY} \mathrm{v} \operatorname{not}(\mathrm{X}) \mathrm{Z}$

$\mathrm{G}(\mathrm{X}, \mathrm{Y}, \mathrm{Z})=\mathrm{XZ} \vee \mathrm{Y} \operatorname{not}(\mathrm{Z})$

$\mathrm{H}(\mathrm{X}, \mathrm{Y}, \mathrm{Z})=\mathrm{X}$ xor $\mathrm{Y}$ xor $\mathrm{Z}$

$\mathrm{I}(\mathrm{X}, \mathrm{Y}, \mathrm{Z})=\mathrm{Y}$ xor $(\mathrm{X} \vee \operatorname{not}(\mathrm{Z}))$

If the bits of $X, Y$, and $Z$ are independent and unbiased, the each bit of $F(X, Y, Z), G(X, Y, Z)$, $\mathrm{H}(\mathrm{X}, \mathrm{Y}, \mathrm{Z})$ and $\mathrm{I}(\mathrm{X}, \mathrm{Y}, \mathrm{Z})$ will be independent and unbiased.

\section{Step 5: Output}

The message digest produced as output is A, B, C, D, i.e., output begins with the low order byte of $\mathrm{A}$ and end with the high order byte of $\mathrm{D}$.

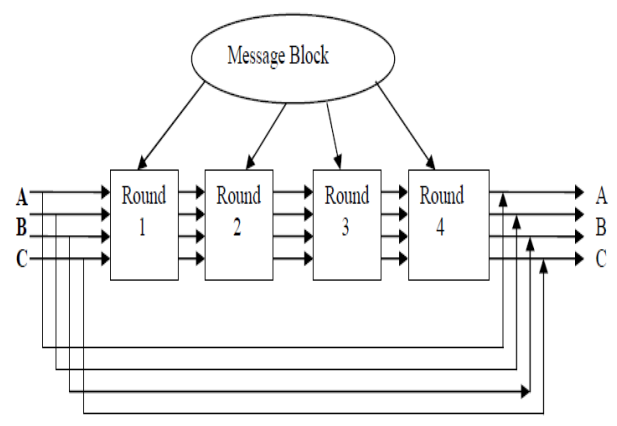

\section{Algorithm 2: Cronjobs Tab}

Cron job are used to schedule commands to be executed periodically. You can setup commands or scripts, which will repeatedly run at a set time. Cron is one of the most useful tool in Linux or UNIX like operating systems. The cron service (daemon) runs in the background and constantly checks the /etc/crontab file, and /etc/cron.*/ directories. It also checks the /var/spool/cron/ directory. crontab is the command used to install, deinstall or list the tables (cron configuration file) used to drive the cron(8) daemon in Vixie Cron. Each user can have their own crontab file, and though these are files in /var/spool/cron/crontabs, they are not intended to be edited directly. You need to use crontab command for editing or setting up your own cron jobs. 


\section{Setting up a Crontab job}

A crontab file consists of lines of six fields each.The fields are separated by spaces or tabs. The first five are integers that specify the following:

1. minute (0-59),

2. hour (0-23),

3. day of the month (1-31),

4. month of the year (1-12),

5. day of the week (0-6 with $0=$ Sunday).

Each of these patterns may be either an asterisk (meaning all valid values) or a list of elements separated by commas. An element is either a number or two numbers separated by a minus sign ( meaning an inclusive range). Notice the time is in 24 hour format, $\mathbf{0}$ is midnight and $\mathbf{1 3}$ is one in the afternoon. The sixth field of a line in a crontab file is a string to be executed by the shell at the specified times by the first fife fields. A percent character in this field (unless escaped by I) is translated to a newline character. Only the first line (up to a \% or end of line) of the command field is executed by the shell. The other lines are made available to the command as standard input. Any line beginning with a \# is a comment and is ignored.

More graphically they would look like this:

$* * * * *$ Command to be executed

- - - -

$|1| \mid$

| | | |+---- Day of week (0-7)

| | |+------- Month (1 - 12)

II +-------- Day of month $(1-31)$

I +-------- Hour $(0$ - 23)

+------------ Min $(0$ - 59

\section{COMPARISON}

\begin{tabular}{|c|c|c|}
\hline & Manual Audit & Automated Audit \\
\hline Time & $\begin{array}{l}\text { By an independent person or body } \\
\text { of persons with the help of } \\
\text { vouchers, documents, information } \\
\text { and explanations received from the } \\
\text { authorities, for the purpose of } \\
\text { ascertaining the work. Hence it } \\
\text { consumes more time }\end{array}$ & $\begin{array}{l}\text { All the works done or not } \\
\text { done can be checked } \\
\text { online.Hence its faster than } \\
\text { Manua audit. }\end{array}$ \\
\hline Responsiveness & $\begin{array}{l}\text { Response is late because a man has } \\
\text { to report to his higher authority. }\end{array}$ & $\begin{array}{l}\text { Quick response when } \\
\text { compared to manual } \\
\text { audit,because the automated } \\
\text { audit works in computerized } \\
\text { environment i e. online. }\end{array}$ \\
\hline Performane & $\begin{array}{l}\text { Performance is slow when } \\
\text { compared to Automated audit } \\
\text { because a man has to do the audit } \\
\text { and inform to the higher authority. }\end{array}$ & $\begin{array}{l}\text { Automated audit works in } \\
\text { the computerized } \\
\text { environment and has become } \\
\text { more relevant so as to make } \\
\text { the audit personnel very } \\
\text { effective in detecting } \\
\text { irregularities. It is the } \\
\text { examination of all } \\
\text { managerial performance. }\end{array}$ \\
\hline
\end{tabular}




\section{CONCLUSION}

Our audit tool works in the computerized environment and has become more relevant so as to make the audit personnel very effective in detecting irregularities. It is the examination of all managerial performance. This software can be used by any organization to keep the rack of all works at their organization. In our audit tool system all the works done or not done can be checked online.

\section{REFERENCES}

[1] http://www.phsa.ca/AboutPHSA/Environmental-Sustainability/Green-Plus-Leaders/default.html.

[2] http://www.phsa.ca/AboutPHSA/Environmental-Sustainability/Green-Plus-Leaders/default.html.

[3] Asian Development Bank (ADB). 2007a. Integrating Capacity Development into Country Programs and Operations. Medium-Term Framework and Action Plan. Manila.

[4] Department for International Development (DFID). 2005. A platform approach to Improving Public Financial Management. London.

[5] Abedi, J., Lord, C., Hofstetter, C., \& Baker, E. (2000). Impact of accommodation strategies on English language learners' test performance. Educational Measurement: Issues and Practices, 19(3), 16-26.

[6] Acquarelli, K., \& Mumme, J. A. (1996). Renaissance in mathematics education reform. Phi Delta Kappan, 77, 478-484.

[7] Blind Citizens Australia (2009). Policy Statement Pedestrian Safety.

[8] Garrard, J (2013). Senior Victorians and walking: obstacles and opportunities, Victoria Walks, Melbourne.

[9] Arter D.R. (1994). Quality Audit for Improved Performance. ASQC Quality Press.

[10] Askey, J M and Dale, B G (1994), Internal Quality Management Auditing:An Examination Managerial Auditing Journal, Vol. 9 No. 4, 1994, pp. 3-10, MCB University Press. 